\title{
Evaluation of Systemic Markers Related To Anemia of Chronic Disease in the Peripheral Blood of Smokers and Non-Smokers with Chronic Periodontitis
}

\author{
Ebru Olgun Erdemira \\ Rana Nalcacib \\ Osman Caglayan
}

\section{ABSTRACT}

Objectives: The aim of this study was to investigate the effect of cigarette smoking on clinical parameters and signs anemia of chronic disease in chronic periodontitis patients.

Methods: The study base consisted of 88 patients with chronic periodontitis including 45 volunteer current smokers with age range of 30-69 $(45.5 \pm 8.5)$ and 43 volunteer non-smokers with age range of 32-61 years (45.8 \pm 7.9$)$. The clinical parameters including plaque index (PI), gingival index (GI), bleeding on probing (BOP), probing depth (PD), clinical attachment loss (CAL) were recorded and several red blood cell parameters were determined from peripheral blood samples.

Results: In smokers, PI, PD and CAL were significantly higher than non-smokers $(P<.05)$. The number of erythrocytes and the levels of hemoglobin, hematocrit and iron were lower in smokers compared to non-smokers $(P<.05)$.

Conclusions: In the present study, it is concluded that cigarette smoking may be effective on the signs of anemia of chronic disease in patients with chronic periodontitis. (Eur J Dent 2008;2:102109)

Key words: Chronic periodontitis; Anemia of chronic disease; Erythrocytes; Hemoglobin; Hematocrit.

\section{INTRODUCTION}

Periodontitis is a multifactorial disease with microbial dental plaque as the initiator of

Kirikkale University, Faculty of Dentistry, Department of Periodontology, Kirikkale, Turkey.

b Kirikkale University, Faculty of Dentistry, Department of Oral Diagnose and Radiology, Kirikkale, Turkey.

Kirikkale University, Faculty of Medicine, Department of Biochemistry, Kirikkale, Turkey.

- Corresponding author:

Ebru Olgun Erdemir

Kirikkale University, Faculty of Dentistry

Department of Periodontology, Kirikkale/TURKEY

Phone: +903182244927

Fax: +903182243618

E-mail: olgun_ebrudyahoo.com periodontal disease. ${ }^{1}$ However, the manifestation and progression of periodontitis is influenced by a wide variety of determinants and factors including subject characteristics, social and behavioral factors, systemic factors, genetic factors, toothlevel factors, microbial composition of dental plaque and other emerging factors. ${ }^{2}$

Smoking is one of the major environmental risk factors for periodontal diseases. ${ }^{3-11}$ In studies where plaque accumulation was similar in smokers and non-smokers or was adjusted, current smokers had deeper probing depths, ,6, 12-14 greater attachment loss, ${ }^{10,12,13,15}$ more bone loss, ${ }^{4,11,16}$ and fewer teeth. ${ }^{13,15}$ Smokers also exhibit more supragingival calculus deposits. ${ }^{17}$ 
It is widely accepted that smoking impairs various aspects of innate and immune host responses. ${ }^{18,19}$ Numerous functions of oral or peripheral neutrophil are negatively affected by smoking or nicotine exposure, including phagocytosis, $^{20}$ superoxide and hydrogen peroxide generation, ${ }^{21,22}$ integrin expression, ${ }^{23}$ and protease inhibitor production. ${ }^{24}$ Alterations in gingival crevicular fluid ${ }^{25-27}$ and peripheral blood mononuclear cell ${ }^{28}$ levels of various cytokines in smokers, tipping the balance in favor of tissue breakdown, have been noted.

Until relatively recently, less attention has been devoted to exploring the role that chronic oral diseases may have on systemic health. The hypothesis that oral conditions, such as periodontal infections, may be risk factors or indicators for important medical outcomes represents a paradigm shift in thinking about causality and the directionality of oral and systemic associations. The subgingival microbiota in patients with periodontitis provides a significant and persistent gram-negative bacterial challenge to the host. These organisms and their products, such as lipopolysaccharide (LPS), have ready access to the periodontal tissues and to the circulation via the sulcular epithelium, which is frequently ulcerated and discontinuous. ${ }^{29}$ It has therefore been speculated that periodontitis results in a low grade systemic inflammation.

Anemia of chronic disease (ACD) is a cytokinemediated anemia commonly encountered in clinical practice and characterized by hypoferramia with adequate reticuloendotelial iron stores, normal to elevated ferritin concentrations and it is a frequent complication of chronic inflammatory conditions. ${ }^{30,31}$ Hutter et $\mathrm{al}^{32}$ suggested that periodontitis has chronic and systemic effects and that periodontitis may tend towards anemia.

The aim of present study was to evaluate the influence of cigarette smoking on clinical parameters and the signs of ACD in patients with chronic periodontitis.

\section{MATERIALS AND METHODS}

\section{Selection of Patients}

The study population included 88 patients, 45 smokers and 43 non-smokers in the age range

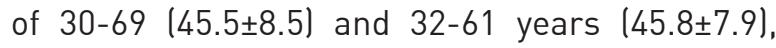
respectively. The patients had chronic periodontitis as evidenced a probing depth of $6 \mathrm{~mm}$ or more at $80 \%$ of the proximal sites and bone loss $>50 \%$ by radiographs. ${ }^{33}$ All participants were in principal periodontally untreated and had not previously received surgical therapy and were drawn from the patients with chronic periodontitis at the Department of Periodontology. All subjects were systemically healthy, with no medical condition that would effect their participation in the study. An extensive medical history was taken both by a written questionnaire and by interview. Exclusion criteria applied were a course of antiinflammatory or antimicrobial therapy within the previous 3 months, a history of use of vitamin or iron supplementation within the previous 3 months, and any special dietary requirements le.g. Coeliac disease). Pregnant women and individuals who suffered, apart from periodontitis, from any given acute or chronic medical condition, including diabetes, viral, fungal or bacterial infections, or had recent trauma or tooth extractions were also excluded. None of them were alcohol consumers. The purpose and nature of the study, including the types of clinical measurements and sample collection, were explained to all potential subjects. After reading and signing the consent form, the subjects were enrolled into the study. The study was approved by the Medical Ethical Committee of our institution.

For all participants smoking habits were recorded and patients were classified as either current smokers [S (+)], i.e., regular daily smoke 20 cigarettes (45 patients), or non-smokers [S (-)], i.e., who had never smoked tobacco (43 patients). All smokers were cigarette smokers. Smoking condition of the patients was calculated as: Number of cigarette per day/number of years smoked. Patients who have been smoking between 15-20 years were included in the study. The mean age of current smokers and non-smokers was $45.5 \pm 8.5$ and 45.8 \pm .9 , respectively. The age differences between groups were not statistically significant ( $P>$.05). Body mass index (BMI) measures of the patients were also recorded and there was not statistically significant difference between groups (P>.05).

\section{Clinical recordings}

Supragingival plaque was scored using Plaque index $(\mathrm{PI})^{34}$ Gingival inflammation was scored using 
Gingival index $(G \mid)^{35}$ Bleeding on probing (BOP) was measured dichotomously. ${ }^{36}$ Probing depth (PD) and clinical attachment level (CAL) measures were obtained from the six points of the teeth using a conventional periodontal probe (Hu-Friedy, Chicago, IL, USA). The probe was directed parallel to the long axis of the tooth. CAL measurements were made from the cemento-enamel junction to the bottom of the sulcus. All clinical data were recorded by one examiner (EOE).

\section{Red blood cell analyses}

Venous blood samples were obtained between 8.30 and $11.00 \mathrm{AM}$ by venepuncture in the antecubital fossa without excessive venous stasis. The blood was taken into EDTA containing vacuum tubes (HEMA, Germany) in the Faculty of Medicine, Department of Biochemistry. The laboratory analysis of differential blood count was performed immediately with the Sysmex XT 2000i Roche, Switzerland).

In standardized and automated procedures, numbers of erythrocytes, hemoglobin, hematocrit, iron, ferritin levels, mean corpuscular volume of erythrocytes (MCV), mean corpuscular hemoglobin $(\mathrm{MCH})$ and the mean corpuscular hemoglobin concentration $(\mathrm{MCHC})$ were calculated.

\section{Statistical analysis}

Data were expressed as means and standard deviations. The statistical significance of differences between groups was tested with Mann Whitney $U$ Test. Simple pair wise correlations were calculated according to the rank correlation of Pearson. The null-hypothesis was rejected at $P<.05$.

\section{RESULTS}

Clinical characteristics

The clinical characteristics of this study are shown in Table 1. When the clinical parameters were compared between groups, in $\mathrm{S}(+)$ group, $\mathrm{Pl}$, $\mathrm{PD}$ and CAL were significantly higher compared to $S(-) \quad(P<.05)$. There were not any differences between smokers and non-smokers in the mean values of $\mathrm{Gl}$ and $\mathrm{BOP}(\mathrm{P}>$.05). Both study groups had a comparable number of teeth present (mean 24.6 smokers and 24.5 for non-smokers). There were no differences between groups with respect to gender.
Serum sample levels of red blood cells

The mean values of serum parameters are shown in Table 2. The number of erythrocytes and the levels of hemoglobin, hematocrit and iron were lower in smokers compared to non-smokers $(\mathrm{P}<.05)$. The MCV, MCH, MCHC and ferritin levels were not different between groups.

\section{Correlations}

Correlations between mean levels of serum and clinical parameters are shown in Tables 3 and 4 for $\mathrm{S}(+)$ and $\mathrm{S}(-)$, respectively. There were no significant correlations between the mean levels of serum parameters and clinical parameters in $\mathrm{S} \mathrm{(-)}$ group ( $P>05)$. In $\mathrm{S}(+)$ group, there were negative correlation between $\mathrm{CAL}$ and the level of RBC in serum values $(P<.05)$, and positive correlations with $\mathrm{Fe}, \mathrm{MCH}$ and $\mathrm{MCHC}(\mathrm{P}<.01)$. In this study group, there were also positive correlations between mean $P D$ values and the levels of $\mathrm{MCV}$ $(P<.05), M C H$ and $M C H C$ in serum $(P<.01)$.

\section{DISCUSSION}

It is now well established from a large body of epidemiologic evidence that cigarette smoking is the major preventable risk factor in the incidence progression of periodontal disease..$^{9,10}$ It is suggested that periodontitis is associated with an increased risk for systemic diseases like cardiovascular diseases, cerebrovascular ischemia and atherosclerosis. ${ }^{37}$ It has been also shown that periodontitis patients have elevated levels of white blood cells, and elevated plasma levels of C-reactive protein. ${ }^{38-42}$ Substantial scientific data indicate that the localized infections characteristic of periodontitis can have a significant effect on the systemic health of both humans and animals. ${ }^{43}$ Just as the periodontal tissues mount an immunoinflammatory response to bacteria and their products, systemic challenge with these agents also induces a majorvascular response. This host response may offer explanatory mechanisms for the interactions between periodontal infection and a variety of systemic disorders. ${ }^{44}$

In the present study, smokers with chronic periodontitis have lower levels of hemoglobin, hematocrit, iron and number of erythrocytes than non-smokers. Ferritin levels were not different between groups. These findings were in parallel direction of the symptoms of ACD. MCV levels 
are the main determinants of the some kinds of anemia. A depressed level of MCV (microcytosis) relates anemia to iron deficiency and elevated level of MCV (macrocytosis) relates anemia to vitamin deficiency. ${ }^{45,46}$ In our study, MCV levels were between the reference values, as mostly seen in ACD and called as normocytosis.

It has been proposed that hepcidin is a primary factor in the pathogenesis of the ACD, a cytokinemediated anemia commonly encountered in clinical practice and characterized by hypoferraemia with adequate reticuloendothelial iron stores. ${ }^{31}$ Previous studies indicated that IL-6 mediates hepcidin increase and consequent hypoferremia during inflammation. ${ }^{47}$ It was found that hepcidin mRNA was increased in the livers of lipopolysaccharide (LPS)-treated mice and LPS-treated hepatocytes. ${ }^{48}$ This also suggested that hepcidin could be the pathogenic mediator of ACD. Kemna et $\mathrm{al}^{49}$ showed the importance of IL-6-hepcidin axis in development of hypoferremia in inflammation and highlight the rapid responsiveness of this iron regulatory system.
Nemeth et $\mathrm{al}^{50}$ found that patients with ACD due to inflammatory disorders or infections had markedly increased excretion of urinary hepcidin. In vitro stimulation of fresh human hepatocytes with a panel of cytokines showed strong induction of hepcidin mRNA by IL-6, but not IL- $\alpha$ or TNF- $\alpha$, indicating that IL-6 may be the mediator of hepcidin induction by inflammation. Although there aren't any studies about the relationship between hepcidin and periodontal diseases or the effect of smoking on hepcidin, it is well known that pro-inflammatory cytokines and mediators are significantly elevated, with gingival inflammation during the destructive phase of periodontitis. ${ }^{51-}$ 56 There is also strong evidence for cytokines eliciting the systemic acute-phase response in various chronic inflammatory diseases. ${ }^{57,58}$ Hutter et $\mathrm{al}^{32}$ suggested that periodontitis also needs to be considered as a chronic disease which may cause lower numbers of erythrocytes and consequently lower hemoglobin levels. They mentioned that the pathogenesis for their findings is similar as reported for rheumatoid arthritis, i.e. depressed

Table 1. The mean values of clinical parameters (mean \pm SD).

\begin{tabular}{lcc}
\hline Parameters & $\mathbf{S}(\mathbf{+})(\mathbf{n}=\mathbf{4 5})$ & $\mathbf{S}(-\mathbf{)}(\mathbf{n}=\mathbf{4 3})$ \\
\hline PI & $2.06 \pm 0.33^{*}$ & $1.79 \pm 0.27$ \\
GI & $1.82 \pm 0.31$ & $1.92 \pm 0.16$ \\
BOP & $0.56 \pm 0.40$ & $0.59 \pm 0.34$ \\
PD & $5.04 \pm 0.61^{*}$ & $4.75 \pm 0.56$ \\
CAL & $4.84 \pm 0.51^{*}$ & $4.41 \pm 0.54$ \\
\hline
\end{tabular}

PI: Plaque index, GI: Gingival index, BOP: Bleeding on probing, PD: Pocket depth, CAL: Clinical attachment loss $*: P<.05$ according to Mann Whitney U Test

Table 2. The mean values of serum parameters in S (+) and S (-) (mean \pm SD).

\begin{tabular}{lcc}
\hline Parameters & $\mathbf{S}(\mathbf{+})(\mathbf{n}=\mathbf{4 5})$ & $\mathbf{S}(-\mathbf{l}(\mathbf{n}=\mathbf{4 3})$ \\
\hline RBC $(106 / \mu l)$ & $4.88 \pm 0.48^{*}$ & $5.17 \pm 0.47$ \\
HGB $(\mathrm{g} / \mathrm{dl})$ & $13.48 \pm 2.19^{*}$ & $14.98 \pm 1.58$ \\
HCT $(\%)$ & $41.39 \pm 5.47^{*}$ & $45.17 \pm 3.84$ \\
FE $(\mu \mathrm{g} / \mathrm{dl})$ & $78.37 \pm 38.62^{*}$ & $97.76 \pm 39.38$ \\
FER $(\mathrm{ng} / \mathrm{dl})$ & $82.16 \pm 49.43$ & $81.39 \pm 86.47$ \\
MCV $(\mathrm{fl})$ & $87.32 \pm 3.83$ & $84.67 \pm 7.38$ \\
$\mathrm{MCH}(\mathrm{pg})$ & $28.97 \pm 2.64$ & $27.55 \pm 3.58$ \\
$\mathrm{MCHC}(\mathrm{g} / \mathrm{dl})$ & $33.18 \pm 2.08$ & $32.48 \pm 2.44$ \\
\hline
\end{tabular}

RBC: Red blood cell, HGB: Hemoglobin, HCT: Hematocrit, FE: Iron, FER: Ferritin MCV: Mean corpuscular volume of erythrocytes, $\mathrm{MCH}$ : Mean corpuscular hemoglobin, $\mathrm{MCHC}$ : Mean corpuscular hemoglobin concentration ${ }^{*}: P<.05$ according to Mann Whitney U Test 
erythropoiesis by systemically circulating proinflammatory cytokines resulting from a local chronic inflammatory process.

Tobacco components may also modify the production of cytokines or inflammatory mediators. In smokers an imbalance in cytokine production seems to occur. Elevated concentrations of IL-6 were observed in the plasma of smokers, ${ }^{59}$ as well as in the alveolar cells of healthy donors stimulated by tobacco glycoprotein. ${ }^{60}$ Nicotine, one of the most deleterious products of cigarette, has been shown to increase release of $1 \mathrm{~L}-6$ by cultured murine osteoblasts. ${ }^{61}$ Giannopoulou et al ${ }^{26}$ indicated that smoking interferes with cytokine production. It has also been reported that release of cytokines from peripheral neutrophils and various parameters of inflammation in plasma seem to be affected more by cigarette smoking than periodontal disease. ${ }^{62}$ Such alterations in host response may affect the reparative and regenerative potential of the periodontium in tobacco smokers. In the literature it has been identified that smoking is an important factor to affect erythrocytes and related parameters. ${ }^{63,64}$ In the present study, our first aim was to detect the effect of smoking on ACD in the existence of chronic periodontitis. Therefore, we did not analyze the inflammatory mediators. But further studies are needed that support the findings of our study with these measurements. The current study indicates periodontitis also needs to be considered as a chronic disease and together with the effect of cigarette smoking it may cause lower numbers of erythrocytes and the levels of hemoglobin, hematocrit and iron.

The BMI measures were also collected due to well recognized effect of adiposity on systemic host response. ${ }^{65,66}$ Nishida et $a^{67}$ suggested that the immunological disorders or inflammation might be the reason that obese smokers tend to exhibit escalating poor periodontal status relative to nonobese and non-smoking individuals. Because of that obese patients were excluded from the study

Table 3. Correlations between serum and clinical parameters in S (+) (n=45).

\begin{tabular}{|c|c|c|c|c|c|}
\hline Parameters & PI & GI & BOP & PD & CAL \\
\hline $\operatorname{RBC}(106 / \mu \mathrm{l})$ & 0.045 & -0.125 & -0.217 & -0.188 & $-0.320 *$ \\
\hline $\mathrm{HGB}(\mathrm{g} / \mathrm{dl})$ & 0.053 & -0.005 & 0.071 & -0.099 & 0.134 \\
\hline HCT (\%) & 0.036 & -0.175 & -0.132 & -0.062 & -0.215 \\
\hline $\mathrm{FE}(\mu \mathrm{g} / \mathrm{dl})$ & -0.083 & 0.069 & 0.243 & 0.186 & 0.331 \\
\hline FER (ng/dl) & -0.060 & 0.026 & 0.031 & 0.192 & 0.147 \\
\hline$M C V(f L)$ & 0.040 & -0.045 & 0.253 & $0.302^{*}$ & 0.277 \\
\hline $\mathrm{MCH}(p g)$ & 0.087 & 0.177 & -0.099 & $0.599 * *$ & $0.525^{* *}$ \\
\hline $\mathrm{MCHC}(\mathrm{g} / \mathrm{dl})$ & 0.053 & 0.277 & -0.109 & $0.609 * *$ & $0.540 * *$ \\
\hline
\end{tabular}

*: The correlation at $P<.05$ level (Pearson correlation coefficients).

**: The correlation at $\mathrm{P}<.01$ level (Pearson correlation coefficients).

Table 4. Correlations between serum and clinical parameters in S (-) (n=43).

\begin{tabular}{|c|c|c|c|c|c|}
\hline Parameters & PI & GI & BOP & PD & CAL \\
\hline $\operatorname{RBC}(106 / \mu \mathrm{l})$ & 0.155 & -0.020 & -0.031 & -0.139 & -0.068 \\
\hline HGB (g/dl) & 0.129 & -0.105 & 0.074 & -0.069 & 0.003 \\
\hline HCT (\%) & 0.086 & -0.167 & -0.078 & -0.224 & -0.162 \\
\hline $\mathrm{FE}(\mu \mathrm{g} / \mathrm{dl})$ & 0.079 & -0.128 & 0.227 & -0.018 & -0.026 \\
\hline FER (ng/dl) & -0.041 & -0.094 & 0.147 & -0.079 & 0.046 \\
\hline MCV $(f l)$ & -0.038 & -0.236 & -0.068 & -0.176 & -0.168 \\
\hline $\mathrm{MCH}$ (pg) & 0.049 & -0.126 & 0.122 & 0.024 & 0.050 \\
\hline MCHC (g/dl) & 0.133 & 0.041 & 0.290 & 0.229 & 0.258 \\
\hline
\end{tabular}

*: The correlation at $\mathrm{P}<.05$ level (Pearson correlation coefficients).

**: The correlation at $\mathrm{P}<.01$ level (Pearson correlation coefficients). 
and also the difference between the groups was not significant.

Some of the studies interpreted the effect of cigarette smoking on the periodontium to be indirect and due to inadequate levels of oral hygiene and increased plaque accumulation among smokers relative to non-smokers. ${ }^{12,68,69}$ In this study, PI levels of S (+) were higher than S (-).

The studies searching the effect of smoking on clinical parameters suggest that non-smokers have higher $\mathrm{GI}$ and BOP values than smokers.3,6,15 But, there are conflicting results those show no significant difference between smokers and nonsmokers ${ }^{70}$ and smokers have higher values than non-smokers. ${ }^{71}$ Pucher et $\mathrm{al}^{72}$ reported that $\mathrm{GI}$ and BOP values were similar in smokers and nonsmokers 9 months after periodontal therapy. In this study, GI and BOP values were found similar in smokers and non-smokers. However, the effects of nicotine has been disputed, some claim that the blood flow is reduced ${ }^{73}$ and others claim it is significantly increased ${ }^{74}$ or unchanged. ${ }^{75}$

The studies which show that PD values were higher in smokers than non-smokers are also present in literature. 3,5,12,16,69,70,76,77 A significant positive correlation has been shown between smoking and CAL. ${ }^{11,15,69,70,77,78}$ In the present study, $P D$ and $C A L$ values were also higher in $\mathrm{S}(+)$ than $\mathrm{S}$ (-). The reason of increased PD and CAL levels in smokers may be depend on accumulation of dental plaque and poor oral hygiene. ${ }^{68,69,79}$ In $\mathrm{S}$ (+) group, it was found negative correlation between CAL and the level of RBC in serum values and positive correlations with $\mathrm{MCH}$ and $\mathrm{MCHC}$. In this study group, it was found positive correlations between mean $\mathrm{PD}$ values and the levels of $\mathrm{MCV}, \mathrm{MCH}$ and $\mathrm{MCHC}$ in serum. According to the results of this study, it seems that smoking is an important factor to affect erythrocytes and related parameters.

\section{CONCLUSIONS}

From the results of the present study, it can be stated that cigarette smoking could have an effect on the numbers of erythrocytes and the levels of hemoglobin hematocrit and iron in serum. Additionally, although cigarette smoking does not affect the degree of gingival inflammation, the amount of dental plaque, probing depth and clinical attachment loss were higher in smokers.

\section{REFERENCES}

1. Kinane DF. Periodontitis modified by systemic factors. Ann Periodontol 1999;4:54-63.

2. Nunn M. Understanding the etiology of periodontitis: an overview of periodontal risk factors. Periodontol 2000 2003;32:11-23.

3. Feldman RS, Bravacos JS, Rose CL. Associations between smoking different tobacco products and periodontal disease indexes. J Periodontol 1983;54:481-487.

4. Bergström J, Eliasson S. Cigarette smoking and alveolar bone height in subjects with high standard of oral hygiene. J Periodontol 1987a;14:466-469.

5. Bergström J, Eliasson S. Noxious effect of cigarette smoking on periodontal health. J Periodont Res 1987b;22:513-517.

6. Bergström J. Cigarette smoking as risk factor in chronic periodontal disease. Commun Dent Oral Epidemiol 1989;17:245-247.

7. Genco RJ, Löe H. The role of systemic conditions and disorders in periodontal disease. Periodontol 2000 1993;2:98-116.

8. Genco RJ. Current view of risk factors for periodontal disease. J Periodontol 1996;67:1041-1049.

9. Bergström J, Preber H. Tobacco use as a risk factor. $J$ Periodontol 1994;65:545-550.

10. Grossi SG, Zambon JJ, Ho AW, et al. Assessment of risk for periodontal disease. I. Risk indicators for attachment loss. J Periodontol 1994;65:260-267.

11. Grossi SG, Genco RJ, Machtei EE, et al. Assessment of risk for periodontal disease. II. Risk indicators for alveoler bone loss. J Periodontol 1995;66:23-29.

12. Linden GJ, Mullally BH. Cigarette smoking and periodontal destruction in young adults. J Periodontol 1994;65:718-723.

13. Haffajae AD, Socransky SS. Relationship of cigarette smoking to attachment level profiles. J Clin Periodontol 2001;28:283-295.

14. Bergström J. Tobacco smoking and risk for periodontal disease. J Clin Periodontol 2003;30:107-113.

15. Axelsson P, Paulander J, Lindhe J. Relationship between smoking and dental status in 35- 50- 65- and 75- year old individuals. J Clin Periodontol 1998;25:297-305.

16. Bergström J, Eliasson S, Dock J. A 10-year prospective study of tobacco smoking and periodontal health. $J$ Periodontol 2000;71:1338-1347.

17. Bergström J. Tobacco smoking and supragingival dental calculus. J Clin Periodontol 1999;26:541-547.

18. Barbour SE, Nakashima K, Zhang JB, et al. Tobacco and smoking: Environmental factors that modify the host response (immune system) and have an impact on periodontal health. Crit Rev Oral Biol Med 1997;8:437-460. 
19. Kinane DF, Chestnutt IG. Smoking and periodontal disease. Crit Rev Oral Biol Med 2000;11:356-365.

20. MacFarlane GD, Herzberg MC, Wolff LF, Hardie NA. Refractory periodontitis associated with abnormal polymorphonuclear leukocyte phagocytosis and cigarette smoking. J Periodontol 1992;63:908-913.

21. Pabst MJ, Pabst KM, Collier JA, et al. Inhibition of neutrophil and monocyte defensive functions by nicotine. J Periodontol 1995;66:1047-1055.

22. Ryder MI, Fujitaki R, Johnson G, Hyun W. Alterations of neutrophil oxidative burst by in vitro smoke exposure: Implications for oral and systemic diseases. Ann Periodontol 1998;3:76-87.

23. Ryder MI, Fujitaki R, Lebus S, et al. Alterations of neutrophil L-selection and CD18 expression by tobacco smoke: Implications for periodontal diseases. $J$ Periodont Res 1998;33:359-368.

24. Persson L, Bergström J, Ito H, Gustafsson A. Tobacco smoking and neutrophil activity in patients with periodontal disease. J Periodontol 2001;72:90-95.

25. Boström L, Linder, LE, Bergström J. Smoking and crevicular fluid levels of IL-6 and TNF- $\alpha$ in periodontal disease. J Clin Periodontol 1999;26:352-357.

26. Giannopoulou C, Cappuyns I, Mombelli A. Effect of smoking on gingival crevicular fluid cytokine profile during experimental gingivitis. J Clin Periodontol 2003;30:9961002.

27. Rawlinson A, Grummit JM, Walsh TF. Interleukin-1 and receptor antagonist levels in gingival crevicular fluid in heavy smokers versus non-smokers. $J$ Clin Periodontol 2003;30:42-48.

28. Ryder MI, Saghizadeh M, Ding Y, Nyugen N, Soskolne A. Effects of tobacco smoke on secretion of IL-1 $\beta$, TNF- $\alpha$ and TGF- $\beta$ from peripheral blood mononuclear cells. Oral Microbiol Immunol 2002;17:331-333.

29. Page RC. Periodontal diseases: a new paradigm. J Dent Edu 1998;2:812-821.

30. Erslev AJ. Anemia of Chronic Disease. In: Beutler E, Lichtman MA, Coller BS, Kipps TJ, Seligsohn U, eds. Williams Hematology McGraw-Hill Professional. New York,USA, 2000:481-488.

31. Means RT. Hepcidin and cytokines in anemia. Hematology 2004;9:357-362.

32. Hutter JW, Van der Velden U, Varoufaki A, Huffels RAM, Hoek FJ, Loos BG. Lower numbers of erythrocytes and lower levels of hemoglobin in periodontitis patients compared to control subjects. J Clin Periodontol 2001;28:930-936.

33. Consensus Report. Chronic periodontitis. Ann Periodontol 1999;4:38-39.

34. Silness J, Löe H. Periodontal disease in pregnancy.
II. Correlation between oral hygiene and periodontal condition. Acta Odont Scand 1964;22:121-135.

35. Löe H, Silness J. Periodontal disease in pregnancy. I. Prevalence and severity. Acta Odontol Scand 1963;21:533551.

36. Ainomo J, Bay I. Problems and proposals for recording gingivitis and plaque. Int Dent $J$ 1975;25:229-235.

37. Scannapieco FA. Position paper. Periodontal disease a potential risk factor for systemic diseases. $J$ Periodontol 1998;69:841-850.

38. Kweider M, Lowe GDO, Murray GD, Kinane DF, McGowan DA. Dental disease, fibrinogen and white cell count; links with myocardial infarction? Scott Med J 1993;38:73-74.

39. Ebersole J, Machen RL, Steffen M, Willman D. Systemic acute-phase reactants, C-reactive protein and haptoglobin, in adult periodontitis. Clin Experiment Immunol 1997;107:347352.

40. Wakai K, Kawamura T, Umemura 0, et al. Associations of medical status and physical fitness with periodontal disease. J Clin Periodontol 1999;26:664-672.

41. Slade GD, Offenbacher S, Beck JD, Heiss G, Pankow JS. Acute phase inflammatory response to periodontal disease in the US population. $J$ Dent Res 2000;79:49-57.

42. Loos BG, Craandijk J, Hoek FJ, Wertheim-van Dillen PME, van der Velden U. Elevation of systemic markers related to cardiovascular diseases in the peripheral blood of periodontitis patients. J Periodontol 2000;71:1528-1534.

43. Ebersole J, Cappelli D. Acute-phase reactants in infections and inflammatory diseases. Periodontol 2000 2000;23:1949.

44. Mealey BL, Klokkevold PR. Periodontal Medicine. In: Newman MG, Takei HH, eds. Carranza's Clinical Periodontology. Philadelphia: Saunders, 2002:232.

45. Ward PC. Investigation of macrocytic anemia. Postgrad Med $J$ 1979;65:203-213.

46. Samson D. The anaemia of chronic disorders. Postgrad Med $J$ 1983;59:543-550.

47. Nemeth E, Rivera S, Gabayan V, et al. IL-6 mediates hypoferremia of inflammation by inducing the synthesis of the iron regulatory hormone hepcidin. $J$ Clin Invest 2004;113:1271-1276.

48. Pigeon C, Ilyin G, Courselaud B, et al. A new mouse liverspecific gene, encoding a protein homologous to human antimicrobial peptide hepcidin, is overexpressed during iron overload. J Biol Chem 2001;276:7811-7819.

49. Kemna EH, Pickkers $P$, Nemeth E, van der Hoeven $H$, Swinkels D. Time-course analysis of hepcidin, serum iron, and plasma cytokine levels in humans injected with LPS. Blood 2005; May 10; [Epub ahead of print] 
50. Nemeth E, Valore EV, Territo M, Schiller G, Lichtenstein A, Ganz T. Hepcidin, a putative mediator of anemia of inflammation, is a type II acute-phase protein. Blood 2003;101:2461-2463.

51. Kinane DF, Adonogianaki E, Moughal N, Winstanley FP, Mooney J, ThornhillM. Immunocytochemicalcharacterization of cellular infiltrate, related endothelial changes and determination of GCF acute-phase proteins during human experimental gingivitis. J Periodont Res 1991;26:286-288.

52. Page RC. The role of inflammatory mediators in the pathogenesis of periodontal disease. $J$ Periodont Res $1991 ; 26: 230-242$.

53. Ranney RR. Immunologic mechanisms of pathogenesis in periodontal diseases: an assessment. $J$ Periodont Res $1991 ; 26: 243-244$

54. Bickel M. The role of interleukin-8 in inflammation and mechanisms of regulation. J Periodontol 1993;64:456-460.

55. Ebersole JL, Singer RE, Steffensen B, Filloon T, Kornman KS. Inflammatory mediators and immunoglobulins in GCF from healthy, gingivitis, and periodontitis sites. $J$ Periodont Res 1993;28:543-546.

56. Tonetti MS, Freiburghaus K, Lang NP, Bickel M. Detection of interleukin-8 and matrix metalloproteinases transcripts in healthy and diseased gingival biopsies by RNA/PCR. $J$ Periodont Res 1993;28:511-513.

57. Kushner I. Regulation of the acute phase response by cytokines. Perspect Biol Med 1993;36:611-622.

58. van Leeuwen MA, van Rijswijk MH, van der Heijde DMFM, et al. The acute-phase response in relation to radiographic progression in early rheumatoid arthritis: a prospective study during the first three years of the disease. $\mathrm{Br} J$ Rheumatol 1993;32:9-13.

59. Tappia PS, Troughton KL, Langley-Evans SC, Grimble RF. Cigarette smoking influences cytokine production and antioxidant defenses. Clin Sci 1995;88:485-489.

60. Francus T, Romano PM, Manzo G, Fonacier L, Arango N Szabo P. IL-1, IL-6 and PDGF mRNA expression in alveolar cells following stimulation with a tobacco-derived antigen. Cell Immunol 1992;145:156-174.

61. El-Ghorab N, Marzec N, Genco R, Dziak R. Effect of nicotine and estrogen on IL-6 release from osteoblasts. $J$ Dent Res 1997;76:341.

62. Fredriksson M, Bergström J, Asman B. IL-8 and TNF- $\alpha$ from peripheral neutrophils and acute-phase proteins in periodontitis. J Clin Periodontol 2002;29:123-128.

63. Ernst E. Haemorheological consequences of chronic cigarette smoking. $J$ Cardio Risk 1995;2:435-439.

64. Maurel A, Apovo M, Beuzard Y, Boynard M, Lagrue G. Influence du tabagisme sur la rheologie sanguine. Journal des Maladies Vasculaires 1997;22:239-243.
65. Tanaka S, Inoue S, Isoda F, et al. Impaired immunity in obesity: Suppressed but reversible lymphocyte responsiveness. Int $J$ Obes Relat Metab Disord; 1993;17:631-636.

66. Stallone DD. The influence of obesity and its treatment on the immune system. Nutr Rev 1994;52:37-50.

67. Nishida N, Tanaka M, Hayashi N, et al. Determination of smoking and obesity as periodontitis risks using the classification and regression tree method. $J$ Periodontol 2005;76:923-928.

68. Preber H, Kant T, Bergström J. Cigarette smoking oral hygiene and periodontal health in Swedish army conscripts. J Clin Periodontol 1980;7:106-113.

69. Zambon JJ, Grossi SG, Machtei EE, Ho AW, Dunford R, Genco RJ. Cigarette smoking increases the risk for subgingival infection with periodontal pathogens. $J$ Periodontol 1996;67:1050-1054

70. van der Weijden GA, De Slegte C, Timmerman MF, van der Velden U. Periodontitis in smokers and non-smokers: intraoral distribution of pockets. J Clin Periodontol 2001;28:955960.

71. Haber J, Wattles J, Crowley M, Mandell R. Evidence for cigarette smoking as a major risk factor for periodontitis. $J$ Periodontol 1993;64:16-23.

72. Pucher JJ, Shibley O, Dentino AR, Ciancio SG. Results of limited non-surgical periodontal therapy in smokers and non-smokers. J Periodontol 1997;68:851-856.

73. Clarke NG, Carey SE. Etiology of chronic periodontal disease an alternative perspective. $J$ Am Dent Assoc 1985;110:689681

74. Baab DA, Öberg PA. The effect of cigarette smoking on gingival blood flow in humans. J Clin Periodontol 1987;14:418424.

75. Meekin TN, Wilson RF, Scott DA, Ide M, Palmer RM. Laser doppler flowmeter measurement of relative gingival and forehead skin blood flow in light and heavy smokers during and after smoking. J Clin Periodontol 2000;27:236-242.

76. Stoltenberg JL, Osborn JB, Philström BL. Association between cigarette smoking, bacterial pathogens, and periodontal status. J Periodontol 1993;64:1225-1230.

77. Machuca G, Rosales I, Lacalle JR, Machuca C, Bullon P. Effect of cigarette smoking on periodontal status of healthy young adults. $J$ Periodontol 2000;71:73-78.

78. Albandar JM, Streckfus CF, Adesanya MR, Winn D. Cigar pipe and cigarette smoking as risk factors for periodontal disease and tooth loss. J Periodontol 2000;71:1874-1881.

79. Ismail A, Burt B, Eklund S. Epidemiologic patterns of smoking and periodontal disease in United States. J Am Dent Assoc 1983;106:617-621. 